\title{
Review and Thinking of Piano Teaching in China's Higher Normal School
}

\author{
Changkui Wang \\ Arts Department of Normal College, Shenzhen University \\ Shenzhen 518060, Guangdong, China \\ Tel: 86-755-2653-6309_E-mail: wangchangkui@163.com
}

\begin{abstract}
Study on piano teaching in China's higher normal school from 2000 to 2008 concentrated on the scope of piano teaching reform, teaching model, collective course, improvisational accompaniment and curriculum and strategy. Unprecedented and brand-new changes have taken place in respects of study content, direction, approach, and perspective, and meanwhile, disadvantages have emerged. Therefore, we should take serious consideration in a classified comment and simple analysis and explore the future direction of study on piano teaching in higher normal school in the new century.
\end{abstract}

Keywords: Higher normal school, Piano teaching, Study

Piano course system in higher normal school is a significant component of pedagogical education system. Analysis, review and summary of the situation and achievements of study on piano teaching in higher normal school facilitates a healthy development of its piano teaching. By analysis of achievements of study on piano teaching in higher normal school from 2000 to 2008, the author analyzes such special subjects as reform of piano teaching, teaching model, collective course, improvisational accompaniment, and teaching method of materials etc, according to proportion of the quantity of theses. Then the author conducts a selective comment and simple analysis, and gives consideration to study on piano teaching in higher normal school.

\section{Academic background of study on piano teaching in higher normal school since the $21^{\text {st }}$ century}

The eight years since the $21^{\text {st }}$ century is the most active period of study on piano teaching in higher normal school in the history.

In July 2000, the editorial offices of $<<$ Piano Artistry $>>$ and $<<$ China Music Education $>>$ organized and held $<<$ Symposium of Piano Teaching Reform in Higher Normal School $>>$ in Beijing. Experts made an analysis of some existing issues in respects of teaching model, skill training and teaching target in higher normal school. Guo Lanlan thought, all schools had always been keeping up to a teaching model in professional conservatory of music, and hadn't had any of its own teaching reform plan with the feature of teacher college. Either their application of music theory or the specific keyboard could achieve a certain height, which would directly influence the future teaching of their students. Mang Feng believed that, we had partially focused on difficulty, greatness and depth of students' performance, but neglected the training of their fundamental application skills, which made it impossible to measure their comprehensive quality and level. Higher normal schools at that time did have the following issues. Their teaching content was limited to the European Classical Romantic Period, with few contemporary chapters or Chinese chapters; there had not any changes in the teaching materials; curriculum design and teaching model were single; positioning of teaching target was not accurate, etc,. The symposium undrew the prologue of exploration in piano teaching reform in the $21^{\text {st }}$ century.

One year later, the Ministry of Education promulgated $<<$ The Musical Curriculum Standard of the Full-time Compulsory Education $>>$. In 2002, the Ministry of Education again promulgated $<<$ Developmental Plan of Art Education in Higher Schools (2001-2010) >>. The new curriculum standard laid emphasis on the new perspective on curriculum after the course integration, which was based on criticism and reflection on the traditional "discipline-based" and "knowledge and skill orientation", and which highlighted the idea of "people-oriented". This perspective on curriculum brought a huge attack to the traditional perspective on curriculum, teaching idea and course establishment.

In September 2004, the Music Education Commission of the Chinese Education Society held $<<$ Piano Seminar of 
Music Education in Higher colleges in China >> in Capital Normal University, and established the "Piano Academic Council. At this conference, representatives present studies and discussed how training norms and piano teaching in higher normal school should adapt to the reform and development of the national basic music education, perfection and innovation of piano course system, piano collective course, training norm of master graduates in the department of music education, the course design and teaching methodology, etc,. The seminar focused on study on the relationship between piano teaching and fundamental music education reform and development.

In September 2006, the Music Education Commission of the Chinese Education Society and the Music Education Society of Chinese Musicians Association co-hosted $<<$ Seminar of Course Development and Teaching Research of Music Education in Higher Colleges >> in Northeast Normal University. Papers about study on piano teaching in higher normal school were respectively discussed in six special subjects. In September in the same year, the Music Education Commission of the Chinese Education Society held $<<$ The Second Seminar of Piano Teaching in Music Education in Higher Colleges and the Second Annual Meeting of the Piano Academic Council >> in Northeast Normal University. The Chief Yang Ruimin pointed out, "how to train qualified teachers for piano education was the target of piano teaching in higher normal school." The seminar distinctly brought into light the significant subject, namely, feature of teachers, and went into further discussion on training of students' teaching capacity, teaching chapter, teaching form and piano teachers' scientific research, etc,.

What was special for that seminar was that $<<$ The First Paper Competition of Piano Teaching in Higher Normal School $>>$ was held. Those thesis were extensive in subject matter, and involved envision of piano courses in higher normal school, and study on piano collective teaching. The study on children material, piano teaching methodology, and Chinese works was new in its perspective and wide in its scope.

The seminar in 2006 was a weather-vine of the extent and depth of study on piano teaching in higher normal school in China.

\section{Study on piano teaching reform}

"Reform" has been a concept that has the highest frequency in study on piano teaching in higher normal school in China since the $21^{\text {st }}$ century. Since the $21^{\text {st }}$ century, several aspects such as study depth, study level and study scope of this subject matter has been further explored from the earliest preliminary understanding, to the subsequent positive implementation and then the current sufficient recognition. Of course, the viewpoint has also been more and more definite.

In the $<<$ Symposium of Piano Teaching Reform in Higher Normal School $>>$ in 2000, Zhou Guangren proposed the target of "one specialty with several capabilities", while Wei Tingge proposed the training target of music education "several specialties and several capabilities". And according to the latter, Those with "several capabilities" of banality couldn't become the final "qualified teachers" in higher normal school. These issues were with themselves a general meaning, and were one of the reasons for piano teaching reform in higher normal school. In terms of course system establishment, Ma Xiaohong believed that, "the school should establish a comprehensive course system of piano art based on the overall requirements of training of music talents and on traditional piano courses, with song accompaniment as the core, and with historical review of piano as the theoretical guidance".

At the beginning of the $21^{\text {st }}$ century, the enrollment of master graduates in piano was expanded, so some new subject matters were introduced, such as training norm of masters in piano, course design, training methodology, and maternal construction etc,. According to Situ Bichun, there were two different directions of training masters in piano, namely, performance and teaching. Masters in piano should lay great importance to the theoretical learning and study of $<<$ Art History of Piano $>>,<<$ Pedagogy of Piano $>>$ and $<<$ Accompaniment Art of Piano $>>$. They should aim at the target of "teaching", and keep course design, thesis writing and educational practice to the point of "application-based talents". There exists a close connection between piano teaching in higher normal school and professional piano teaching in conservatory of music, but there also has a clear and essential differences between the two, which include training target, source of students, teaching task and teaching time, etc,. Therefore, we should strengthen teaching of basic theory in piano teaching, intensify piano and song accompaniment capacity, open up artistic history courses of piano about China and foreign countries, and bring piano teaching methodology into teaching content and approaches of reform and evaluation.

In his $<<$ The Two-dimensional Illustration of Piano Teaching Connotation in Higher Normal School --- a Translation Based on Music Aesthetic Culture and Cultural Heritage $>>$, Gao Wei made a new and philosophical analysis about cultural meanings of piano teaching reform in higher normal school from the perspective of music aesthetic culture and cultural heritage. In the $<<$ Piano Teaching Should Focus on Piano Music Culture $>>(<<$ Journal of Xinghai Conservatory of Music >>, No.2, 2004), Du Sichun also believed that, piano teaching should focus on learning of piano music culture, and mentioned the importance of piano music culture in piano teaching. This is a subject seldom studied by piano teaching in higher normal school. 


\section{Study on piano teaching model and collective course}

\subsection{Study on piano teaching model of higher normal school}

It has been for quite some time since the discussion on piano teaching model in higher normal school. Since the $21^{\text {st }}$ Century, scholars have, without exception, persisted in their own viewpoints, but what is unanimous is that the fixed one-to-one teaching model has been for long an important hindrance of piano teaching reform and development. In 2002, the article $<<$ Primary Exploration of Piano Teaching Model in Higher Normal School $>>$ by He Lv $\left(<<\right.$ Explorations in Music $>>$ No.2, 2002) was an investigation in teaching model in the earlier $21^{\text {st }}$ century. The author summarizes reasons for reform of piano teaching model in higher normal school as follows: expansion of enrollment causes fewer teachers and more students, and serious shortage of teaching sources; then the training target of the feature of teachers. This analysis is relatively objective. Therefore, the author advocates to open up piano theoretical course, piano collective course and piano appreciation course. The article by Huang Yin $<<$ Reflection and Practice of Expansion of Piano Teaching Approach in Higher Normal School $>>(<<$ Music Research $>>$ No.1, 2007) provides with us a different referential teaching approach. In his $<<$ Study on the Plural Teaching Model in Higher Normal School $>>$ $(<<$ Music Exploration $>>$ No.2, 2002), Chen Guangquan for the first time put forward the concept of plural piano teaching model, and further demonstrated from three aspects the viewpoint that application of plural teaching model in piano teaching in higher normal school is an effective carrier to train students' comprehensive capacity.

\subsection{Study on piano collective course in higher normal school}

At the symposium of piano teaching reform in higher normal school in 2000, Zhou Guangren advocated to open up piano collective course. She said, 'It's a pity that, piano collective course still hasn't been universally accepted by our teachers and students, and this teaching approach is still in its experimental phase." When the year 2007 arrived, we discovered that a large majority of higher normal schools had adopted the form of collective course in their piano teaching. From Zhou Guangren's appealing to promotion of this form up to now, only less than ten years have passed. This form is developed rapidly with the pace of higher education reform in China, and is a teaching reform project among all musical teaching reforms in recent year that is most rapidly developed, has the most extensive influential scope, and has the largest teaching scale. And it is also a remarkable event in musical education reform in the $21^{\text {st }}$ century.

In his article $<<$ Development of $<$ Piano Collective Course $>$ in Normal Education in China $>>(<<$ Piano Artistry $>>$ No.12, 2004), Li Heping gave a historical review on development of piano collective course, and presented the introduction of teaching methodology of American keyboard collective course by normal schools as well as the situation of their research and experiments. Since the introduction of piano collective course, more and more teachers have been positively practiced and summarized experiences. For instance, in his $<<$ Application of MIDI Library of Exemplary Piece in Piano Collective Course in Higher Normal School $>>(<<$ Journal of Xiaogan University $>>$ No.1, 2004), Yang Dehua gave comments on methods of combination of piano collective course with multimedia teaching. A large majority of teachers submitted their experimental report on piano collective course teaching, such as $<<$ Report on Research of Digital Piano Collective Course in Higher Normal School $>>(<<$ Journal of Hubei Institute of Education $>>$ No.3, 2006). As for the subject of exploration in learning model of piano collective course, in his article $<<$ exploration and Practice of Research-based Learning model of Piano Collective Course in Higher Normal School $>>(<<$ Piano Artistry $>>$ No.1, 2007), Ma Tanghua held the view that, "in the piano collective course, we should establish "an inquiry learning model based on problem resolution"'. He further studied collective course from the perspective of learning theory. What should be mentioned, scholars began to study collective course from the perspective of a new educational theory. In the article $<<$ The Theory of Multiple Intelligences and Reform of Piano Collective Course Teaching in Higher Normal School $>>(<<$ Chinese Music $>>$ No.4, 2006), Wang Yihong applied Gardner's theory of multiple intelligences, and analyzed disequilibrium between intellectual and nonintellectual structures in piano teaching. "We should try to teach piano collective course from a new perspective by means of application of the theory of multiple intelligences in piano collective course", which brings a brand-new research field of view and enlightenment.

Digital piano has become the primary teaching instrument in collective course. In the article $<<$ Application of Digital Piano Teaching System in Musical Education in Higher Normal School $>>(<<$ Beauty \& Times $>>$ No.7, 2008), Yang Jing held the view that, digital piano teaching system was combination of piano and modern high-tech, and was a newly born teaching idea and method. Compared with the traditional piano teaching system, the digital piano teaching system has changed the traditional model of former single teaching, widened content of piano teaching and has largely increased efficiency of piano teaching. Simultaneously, it organically combines knowledge of other subjects, and strengthens lateral linkage and intersecting interpenetration among different disciplines. In $<<$ Discussion on a New Model in Piano Teaching in Higher Normal School --- Feasibility of Teaching of Digital Piano Collective Course $>>$, Liu Lei advocated to explore the modern "one-to-many" digital collective course teaching, to try hard to implement the brand-new trinitarian teaching method of skill, appreciation and innovation, to adapt to requirements of teaching reform and development of the era, and to keep up with targets of all-around development education and training in the $21^{\text {st }}$ 
century. She held a positive attitude towards digital piano teaching. However, there is still a long way to in terms of the study depth and breadth.

\section{Study on improvisational accompaniment of piano}

Improvisational accompaniment of piano in higher normal school is a course with great practicability and close connection with other subjects. Therefore, it demands high comprehensive quality on teachers, and is also one of hot topics in the $21^{\text {st }}$ Century.

In the symposium of piano teaching reform in 2000 , it was unanimously agreed that teachers were far from satisfaction in terms of their teaching ability, teaching level and teaching method about improvisational accompaniment. Therefore, we should first of all train qualified teachers, and then improve accompaniment materials. Wei Tingge held an opposite view. According to him, "Essentially, improvisational accompaniment is not teachable, and what can be taught is only piano skill and composition technical theory". The symposium proposed a controversy to that view. In the article "Status Quo of Piano Improvisational Accompaniment Teaching and Reflection on it" $(<<$ Journal of Guizhou University >> No.4, 2004), Liu Zhu thought that "appropriate consideration of the position of piano improvisational accompaniment in the entire teaching and coordination of improvisational accompaniment with teaching reform of courses such as piano, harmony and Harmonic Ear, etc, play a positive role." In the article $<<$ Exploration and Practice of Teaching Reform of Piano Improvisational Accompaniment Course in Higher Normal School $>>(<<$ China Music Education $>>$ No.5, 2005), Zhang Hui and Zhou Dongmei held the opinion that, introduction of "non-teaching factor" in the process of teaching would break the traditional teaching model concentrating on teaching. They suggested that adoption of a heuristic and leading teaching method would be an effective model of accompaniment course, and their practical experiences were worth to be advocated. In the $<<$ Brief Analysis of Learning of Piano Improvisational Accompaniment $>>(<<$ People's Music $>>$ No.1, 2007), Jiang Ying thought that, "the capacity of an accurate, speedy and expressive improvisational accompaniment is a significant capacity teachers should acquire, and is also the primary factor in teaching and assessment. Therefore, training strategy of design of improvisational accompaniment course should center with the three emphasis.” This viewpoint is directly to the point of the key in current improvisational accompaniment course. It is the key whether we should teach our students on the basis of training the necessary improvisational accompaniment capacity in music teachers in primary and secondary schools.

\section{Study on teaching of piano teaching materials}

$<<$ Pedagogy of Piano $>>$ in higher normal school is a new course in the $21^{\text {st }}$ Century, and research of this subject is still in its preliminary stage at present. In $<<$ Seminar of Course Development and Teaching Research of Music Education in Higher Colleges $>>$ in 2006, and in his remark about $<<$ Discussion on Property and Design of Teaching Model of $<$ Piano Literature and Teaching Method $>$, Wang Changkui put forward for the first time the design theory of pyramid-style teaching model of $<<$ Piano Literature and Teaching Method $>>$. He designed five parts of teaching model of the course, and advocated the viewpoint that, teaching theory with hierarchical coordination, and development of individualized and elastic teaching theory is an effective approach for a more scientific and rational design of teaching model.

In the $<<$ Preliminary Exploration of $<$ Pedagogy of Piano $>$ in Higher Normal School $>>(<<$ Piano Artistry $>>$ No.8,2004), Ma Tanghua thought that, $<<$ Pedagogy of Piano $>>$ had better resolved the urgent demand of qualified piano teachers in amateur piano education, but this course usually gave priority to teaching of book theory, difficult to stimulate and adjust students' learning motive. Students in normal school should go deep into practice and learn theories in practical learning. In the article $<<$ Enlightenment of Constructivism Teaching on Piano Teaching In Higher Normal School $>>(<<$ Music Works $>>$ No.4, 2007), Liu Min analyzed methods of piano teaching in higher normal school by means of the constructivism theory and held her own original ideas.

Since the $21^{\text {st }}$ century, few people have conducted studies on piano teaching materials in higher normal school, which are mostly introductive articles. In his article $<<$ Discussion on Selection of Teaching Materials of Piano Collective Course in Higher Normal School --- together with Practical Value of the Course $<$ Basic Training of Piano Playing $>$ by Zhou Guangren $>>(<<$ Piano Artistry $>>$ No.10, 2003), Yang Xiangyong believed that, "teaching and training of skills should become the center of piano teaching". The course of $<<$ Basic Training of Piano Playing $>>$ by Zhou Guangren has eight advantages to be promoted. In 2004, People's Music Publishing House published $<<$ Teaching Material of Brand-new Digital Piano Collective Course $>>$. Li Meige visited America for an investigation of piano collective course earlier, and she set about teaching experiment on it soon after returning to China. In the $<<$ Seminar of Piano Teaching Reform in Higher Normal School $>>$, Li Meige introduced this set of teaching material. In his $<<$ New Course, New Teaching Material and New Teaching Method --- Discussion from $<$ Teaching Material of Brand-new Digital Piano Collective Course $>>>$ (Piano Artistry $>>$, No.3, 2005), Xu De introduced the four characteristics of this set of teaching material, namely, keyboard theory and transfixion of knowledge, sight-playing and transposition teaching, solo and ensemble teaching and creation and style simulation teaching. Publication and implementation of this set of teaching material would be a breakthrough of piano collective course teaching reform in higher normal school. In $<<$ The Second 
Seminar of Piano Teaching in Music Education in Higher Colleges and the Second Annual Meeting of the Piano Academic Council $>>$ in 2006, Tang Chongqing introduced the undergraduate musicology teaching material of $<<$ Piano $>>$ published by People's Music Publishing House and edited by Zhang Hui, Tang Chongqing and Li Heping. This set of teaching material has received a unanimous recognition by piano teachers in terms of its focus on the feature of teachers and its reveal of capacity training, and will play an improving role in a healthy development of piano teaching in higher normal school.

Under the circumstance in which universal piano education has become the dominant channel for exchange of Chinese music culture and the global music culture, Huang Ying advocates to combine Chinese piano literature and significant Occidental piano literature in basic teaching of piano, and to promote these two complementary cultures. She also proposes the envision of nationalization of fundamental piano teaching materials and creation of Chinese Pianolude.

\section{Conclusion and thinking of study on piano teaching since the new century}

A brief review on research of piano teaching from 2000 to 2007, we discover that there are the following characteristics for research of this period.

1). In terms of the content, study emphasis of this period relatively concentrated on such subjects as teaching reform, course system establishment, teaching model, and collective course form etc, and the study of this period was close to the pace of contemporary information and educational reform, so it has played an improving role in promotion of piano teaching in higher normal school. Its influential force is self-evident. However, width and depth of study in terms of teaching method of materials, role of Chinese works in teaching and fundamental teaching, etc,.

2). In terms of the direction, study of this period began to switch to the direction of fundamental music education and social fundamental music education, but the integration has not been enough.

3). In terms of the method, most studies adopted experiential summary method, which was practical and feasible. However, few studies adopted empirical methods, and some studies were short of reliable data, so the argument was not enough and was not convictive.

4). In terms of the perspective, comparative study of piano teaching in foreign higher normal school was lacking. Study was relatively weak by means of a new educational teaching theory and a new perspective. Furthermore, there were fewer studies from the perspective of aesthetics, philosophy and culturology, and academic profoundness is still open to be strengthened.

In brief, we get the following thought and prospects for study on piano teaching in higher normal schools in the future.

1). To reform the concept of teaching research, and to strengthen service of piano teaching research for fundamental music education and for social fundamental piano teaching. To focus on development of fundamental music education and social fundamental piano teaching, and to open the research fields.

2). To intensify theoretical research of teaching methodology of piano teaching materials, and to explain the modern piano teaching methodology that are changing with an astounding speed by means of a new educational theory and educational concept. The research should be forward-looking, and it should be avoided to remain at a level of empirical and introductive research.

3). Emphasis on music culture of the nation has been a tendency of study on international music education in recent years. To strengthen research and summary of teaching of Chinese piano works in piano teaching in higher normal school, to put forward a theoretical basis for the new piano teaching materials with national characteristics, and to provide practical evidence for piano teaching.

4). Research of piano teaching in higher normal school should establish a multicultural music concept, and broaden research content and scope. For instance, to broaden comparative study of piano teaching in foreign higher normal school, to connect intersecting research of others subjects in the department of music education, and to apply intersecting research of such theories as modern pedagogics, psychology, and sociology, etc. Therefore, research of piano teaching can obtain a new value orientation at a further level.

We believe that, in the near future, with common efforts of a large number of experts and scholars, study on piano teaching in higer normal school will get more varied, and will promote more effectively forward development of piano teaching in higher normal school.

\section{References}

Liu, Xiaolong. (2001). Summary of the Symposium of Piano Teaching Reform in Higher Normal Colleges. Beijing: Piano Artistry, (1).

Lv, Qi. (2006). Emphasis on the Character of Teachers, and Acceleration of Pace of Piano Teaching Reform in Higher Normal School --- Convene of the Second Piano Seminar of Music Education Major in Higher Education. Beijing: People's Music, (12). 
Xiaohui. (2000). Instructive Exploration of Piano Teaching in Higher Normal School --- Summary of the Symposium of Piano Teaching Reform in Higher Normal School. Beijing: China Music Education, (10).

Xu, Bing \& Ma, Da. (2007). Recollection and Prospect of Music Education Teaching Reform in Higher Education in China --- Summary of "Seminar of Course Development and Teaching Research in Higher Education in China" in 2006. Beijing: People's Music, (3).

Zhang, Xuliang. (2004). Piano Rhythm, ingenuity and Hope --- Record of the 2004 "Piano Seminar of Music Education Major in Higher Education". Beijing: Piano Artistry, (11). 